ELEMEN ESTETIS KOREOGRAFI TARI CANG-CANG DI KAYUAGUNG KABUPATEN OGAN KOMERING ILIR

Emy Admala Yuliarti

KONSEP KEBERSAMAAN DALAM TRADISI MIDANG MABANG HANDAK PADA MASYRAKAT MORGESIWE KECAMATAN KAYUAGUNG

A. Heryanto

PANGLIMA LAOQT SEBAGAI LOCAL WISDOM MASYARAKAT NELAYAN PESISIR ACEH (STUDI KASUS TENTANG PANGLIMA LAOQT LHOK KECAMATAN SERUWAY KABUPATEN ACEH TAMIANG)

Purnama Sari \& Puspitawati

PENERAPAN MODEL PEMBELAJARAN COURSE REVIEW HORAY TERHADAP KEMAMPUAN MENJELASKAN ALUR CERPEN UNTUK ANAK SDN 52 PALEMBANG Sri Wahyu indrawati

PENGARUH MODEL PEMBELAJARAN ARTIKULASI TERHADAP KEMAMPUAN MENULIS PADA SMP NEGERI 2 PALEMBANG

Yus Vernandes Uzer

PENGARUH MODEL PEMBELAJARAN COMPLETE SENTENCE TERHADAP KEMAMPUAN MENULIS PADA SMP NEGERI 13 PALEMBANG

Yuspar Uzer

$60-70$

PENGARUH MUSIK ANSAMBEL TERHADAP KECERDASAN EMOSI REMAJA

Novdaly Fillamenta \& Mohammad Arfani

PEWAISAN RABAB PIAMAN DI KECAMATAN LUBUK ALUNG

KABUPTEN PADANG PARIAMAN

Irfan Kurniawan

$82-93$

ESTETIKA MOTIF NAGO BESAUNG PADA KAIN SONGKET PALEMBANG Decky Kunian

BENTUK GERAK TARI KAIN DI SANGGAR DEWAN KESENIAN MUSI RAWAS

Pransiska Sepriyanti 


\title{
ESTETIKA MOTIF NAGO BESAUNG PADA KAIN SONGKET PALEMBANG
}

\author{
Oleh: \\ Decky Kunian \\ (Dosen FKIP Universitas PGRI Palembang)
}

\begin{abstract}
Abstrak
Penelitian ini bertujuan untuk mengungkap keindahan motif Nago Besaung pada kain songket palembang. Melalui teori Monroe Beardsley yang menjelaskan "ada 3 (tiga) ciri yang menjadi sifatsifat membuat baik/indah dari benda-benda estetis yaitu: unity, penerapan motif nago besaung dalam penataanya menimbulkan harmonisasi ketika deretan motif pokok dan motif pengisi, serta motif isen yang berada pada satu bidang motif yang berada pada badan kain. Selain itu motipmotip pengisi yaitu motif bungo mawar dan motif bungo melati ini berfungsi sebagai penguat atau penegasan entetitas terhadap motif pokoknya yang diatur sedemikian rupa sehingga memiliki nilai estetis. Sedangkan motif isen memberikan penegasan yang kuat yang lebih mengarah kepada kompleksitas dan estetis. Complexity tampak pada tahap menenun kain dasar dengan konstruksi tenunan rata atau polos dan tahap menenun bagian ragam hias yaitu menenun motif nago besaung itu sendiri yang merupakan bagian tambahan dari benang pakan, dengan demikian kerumitannya pun sudah bisa dirasakan. Serta intensity tampak terlihat secara visual dimana bentuk motif nago besaung menampilkan tingkat kesungguhan yang tinggi yang ditunjukkan dalam tingkat kreativitasnya dengan menerapkan berbagai motif (pokok, pengisi, dan isen) yang dikomposisikan sedemikian rupa sehingga akan tampak keharmonisan di dalamnya serta kesungguhan yang dapat dirasakan dari emosional/rasa yang menampilkan sejumlah motif baik motif pokok maupun motif pengisi yang merefleksikan nilai atau makna kehidupan sosial masyarakat Palembang.
\end{abstract}

Kata Kunci, Estetika, Motif Nago Besaung, Songket Palembang

\section{A.PENDAHULUAN}

Songket Palembang umumnya hadir sebagai nilai tambah estetis suatu karya, yang kadang bukan hanya sebagai sarana dalam mempercantik karya tetapi sebagai media penting untuk membuat karya itu ada. Selembar kain tidak bisa disebut songket bila tidak memiliki ragam hias. Ragam hias itulah yang membuat tenun songket memiliki nilai seni yang tinggi, karena ragam hias adalah ungkapan perasaan dari penciptanya. Ragam hias juga merupakan wujud dari keinginan masyarakat pendukungnya.

Sesuai dengan pendapat Soegeng Toekio bahwa seni sebagai bagian dari budaya, ia senafas dengan masyarakat pendukungnya. la seiring dengan seniman penciptanya. Oleh karenanya desain baru yang diungkap seniman pun merupakan cetusan atau 
ciptaan yang didasari tata kehidupan dirinya (1983/1984: 133). Sebagai karya seni songket harus menampilkan nilai estetik atau nilai keindahan visual atau rupa, sedangkan sebagai seni terapan, nilai estetik songket tidak dapat dipisahkan dari nilai gunanya, selain itu nilai teknis juga menentukan kualitas karya seni tenun songket sebagai. Nilai estetik pada motif songket berkaitan dengan konsep ornamentik seni hiasnya yang menggunakan simbol-simbol magis sebagai konsep berpikir yang menjadi falsafah hidup dan budaya masyarakat pendukungnya.

\section{B.METODELOGI PENELITIAN}

Adapun metode penelitian yang digunakan dalam penelitian ini yaitu metode kualitatif dengan melakukan pendekatan menggunakan teori Moenroe Beardsley.

\section{HASIL DAN PEMBAHASAN}

Teori Monroe Beardsley menjelaskan "ada 3 (tiga) ciri yang menjadi sifat-sifat membuat baik/indah dari benda-benda estetis yaitu: kesatuan (unity) yang bearti bahwa benda estetis ini tersusun secara baik atau sempurna bentuknya, kerumitan (complexity) benda estetis atau karya seni yang bersaangkutan tidak sederhana sekali, melainkan kaya akan isi maupun unsurunsur yang saling berlawanan ataupun mengandung perbedaan-perbedaan yang halus, dan kesungguhan (intensity) yang berarti suatu benda estetis yang baik harus mempunyai suatu kualitas tertentu yang menonjol dan bukan sekedar sesuatu yang kosong, tak menjadi soal kualitas apa yang dikandungnya (misalnya suasana gembira atau suram, sifat lembut atau kasar), asalkan merupakan sesuatu yang intensif atau sungguh-sungguh".

\section{Kesatuan (Unity)}

Dharsono Sony Kartika menegaskan dalam bukunya seni rupa modern bahwa: kesatuan adalah kohesi, konsistensi, keutuhan yang mrupakan isi pokok dari komposisi. Kesatuan merupakan efek yang dicapai dalam suatu susunan atau komposisi diantara hubungan unsur pendukung karya, sehingga secara keseluruhan menampilkan kesan tanggapan secara utuh (Dharsono, 2004: 59).

Motif nago besaung dapat dikatakan sebagai karya seni bernilai tinggi karena keindahannya yang 
menakjubkan. Keindahan tersebut dibangun melalui pengorganisasian atau penyususunan yang terpadu disetiap elemen-elemen yang dikomposisikan pada motif pokok menjadi satu kesatuan yang utuh. Motif tengah (badan) kain adalah motif yang ditempatkan berada di tengah kain. Motif ini dapat dikatakan pula sebagai motif pusat karena terletak ditengah-tengah suatu bidang atau benda (Suprihatin, 2007: 16).

Pada motif nago besaung akan elemennya, sehingga akan tampak motif yang menjadi unsur pokoknya (motif yang berada dibadan kain). Kesatuan yang terlihat dari motif nago besaung tersebut dapat terlihat pada tiga bagian motif, yaitu: 1) motif pokok (motif naga), 2) motif pengisi (mawar sebagai motif pengisi dalam motif pokok, dan melati sebagai motif pengisi luar) dan motif isen (sebagai penambah nilai estetis), berikut merupakan gambaran motif nago besaung pada kain songket Palembang; tampak pembagian bagian elemen-


Gambar 2: Motif nago besaung, bungo mawar dan bungo melati. (dok. Decky, 2019) 
Penerapan motif nago besaung merupakan hasil stilasi dari motif makhluk hidup, walaupun naga merupakan makhluk imajinatif tetapi oleh masyarakat Palembang meyakini keberadaannya. Atas dasar pola pikir itulah bentuk naga yang dituangkan dalam songket merupakan ungkapan kekuatan, kebijaksanaan, kemegahan, kejayaan ataupun kehebatan yang tentunya digambarkan dalam wujud yang berbeda dan juga tentunya telah mengalami kesepakatan bersama dalam kosepsi penyimbolan dari naga tersebut. Senada dengan Toekio bahwa beberapa jenis binatang diangkat secara syimbolis mewakili suatu makna tertentu, ia bisa mewakili tentang satu kekuatan, keperkasaan, dinamis, kokoh, angkuh, cerdik, sakti dan sebagainya (1983: 121).

Jika diperhatikan pada gambar 1 , penerapan bentuk naga yang sama tetapi diletakkan berbeda dan terjadi pengulangan-pengulangan nampak sekali. Diantaranya menyatu, karena komposisi yang dibuat disusun sedemikian rapat. Sehingga kita akan melihat motif nago besaung lebih tampak memberikan kesan yang berat (lebih menonjol) pada badan kain dibandingkan motif pendukung (bungo mawar (motif isian pada motif pokok) dan bungo melati (sebagai motif selingan)). Sependapat dengan Toekio bahwa dengan cara pengulangan yang mengambil ukuran tetap sebagai pola-ulang dapat dicapai sedemikian rupa yang tentu saja dengan pertimbangan ritme maka gambar akan menjadi kaku atau monoton, hal ini mengakibatkan kejenuan pandangan kita (1983: 17).

Bidang yang mengisi pada motif naga juga memberi andil penting dalam hal ini, karena dari pengisian bidang garis pada motif nago betarung terlihat lebih berat (menonjol) hal tersebut tentunya secara tidak langsung dapat memberikan rangsangan kepada kita (penonton) untuk menyampaikan suatu kesan didalamnya. Bidang tersebut digambarkan lengkung simetris yang mebentuk pola empat dengan bunga mawar sebagai pusatnya yang tersusun secara harmonis dalam satuan komposisi.

Komposisi penempatan motif nago besaung ditempatkan secara penuh dan motif hiasnya saling bertautan pada bidang kain tenun songket. Penempatan motif hias bunga mawar dan bunga melati penempatannya diatur dengan jarak antara motif satu dengan 
lainnya sehingga ada sela-sela bidang yang kosong. Secara keseluruhan semua motif hias tersebut diatur sedemikian rupa sehingga memiliki nilai estetis.

Penataan ragam hias tenun songket motif ini ditampilkan secara berulang-ulang secara teratur tentunya akan terlihat berirama. Pengulangan pengaturan motif hias tergantung dari jenis motif hias yang diterapkan (baik pada tepi, badan dan kepala kain). Pengaturan disini dimaksudkan motifmotif yang sama disusun secara berulang-ulang tetapi tidak monoton sehingga secara keseluruhan tampak adanya irama. Irama dapat ditampilkan melalui pengaturan bentuk motif hias seperti: besar, kecil, tinggi, rendah, panjang, dan pendek seperti yang tampak pada badan kain khususnya.

Jika melihat keharmonisan penempatan ragam hias tenun songket motif nago besaung dapat dilihat pada penyusunan motif hias maupun penampilan warna secara keseluruhan kain tenun songket tersebut. Sesuai dengan pemakaian benang untuk kain tenun, maupun motif-motif hias tenunnya, serta warna yang ditampilkan secara keseluruhan dipandang dari nilai-nilai estetikanya sangat harmonis. Karena disini ada keselarasan dalam penempatan motif cukup terpadu, penyusunan warna pada motif yang komplementer dan tidak ada yang mengalami pertentangan pertentangan.

Lebih jauhya keseimbangan penempatan ragam hias pada badan songket motif nago besaung terlihat sangat seimbangan. Keseimbangan yang dimaksudkan adalah karena tidak akan menimbulkan kesan berat sebelah. Secara umum penempatan ragam hias kain tenun songket motif nago besaung konsep seimbang sangat tampak. Kesimbangan karena penempatan motif hiasnya sama secara berulang-ulang secara penuh pada bidang kain. Seperti pada motif badan kain, motif naga, bunga mawar, dan bunga melati pada penempatan motifnya menyebar dan tidak ada kesan yang berat sebelah. Menyinggung sedikit pada motif kepala dan motif hias pinggir keseimbangannya terlihat pada hiasan pokok dan hiasan pinggirnya. Hiasan pinggiran pada bagian atas dan bawah, hiasan pinggir kanan dan kiri dibuat seimbang sehingga tidak ada yang berat sebelah.

Penerapan motip-motip tersebut dalam penataanya semakin 
memunculkan harmonisasi ketika deretan motif pokok dan motif pengisi, serta motif isen yang berada pada satu bidang motif yang berada pada badan kain. Selain itu motip-motip pengisi yaitu motif bungo mawar dan motif bunga melati ini berfugsi sebagai penguat atau penegasan entetitas terhadap motif pokoknya. Penempatan motif hias bunga mawar dan bunga melati penempatannya diatur dengan jarak antara motif satu dengan lainnya sehingga ada sela-sela bidang yang kosong. Secara keseluruhan semua motif hias tersebut diatur sedemikian rupa sehingga memiliki nilai estetis. Sedangkan motif isen memberikan penegasan yang kuat yang lebih mengarah kepada kompleksitas dan estetis. Hal tersebut menghantarkan mata para penonton tertuju pada seluruh motif yang berada di dalamnya, sehingga memunculkan kesan kesatuan di mana motif pokok menjadi fokus dari keseluruhan motif di dalam songket.

\section{Kerumitan (Komplexity)}

Mendapatkan karya seni bercitarasa tinggi tentu tidak lepas dari tingkat kerumitan pada suatu karya yang dihadirkan oleh senimannya melalui konsep yang matang dan ditunjang oleh teknik maupun media yang dipergunakan sama halnya dengan yang terjadi pada pembuatan songket. Kerumitan merupakan suatu ciri benda estetis atau karya seni yang bersangkutan tidak sederhana sama sekali, melainkan kaya akan isi maupun unsur-unsur yang saling berlawanan ataupun mengandung perbedaan-perbedaan yang halus Moenro Beardsley dalam Dharsono (2007: 63).

Mengacu pada pemikiran Moenro Beardsley terkait dengan hal kerumitan maka dalam proses pembuatan motif nago besaung pada songket Palembang ini pada dasarnya dilakukan dalam dua tahap, yaitu: tahap menenun kain dasar dengan konstruksi tenunan rata atau polos dan tahap menenun bagian ragam hias yaitu menenun motif ngo besaung itu sendiri yang merupakan bagian tambahan dari benang pakan, dengan demikian kerumitannya pun sudah bisa dirasakan.

Pemaparan yang lebih lanjut penulis akan sedikit menyinggung bagaimana kerumitan yang terjadi dalam proses pembuatan motif nago besaung, dimulai dari bahan baku kain songket motif ini yaitu terdiri dari berbagai jenis 
benang, seperti benang kapas, atau yang lebih lembut dari bahan benang sutera. Untuk membuat kain songket yang bagus, bahan bakunya berupa benang putih yang diimpor dari India, Cina atau Thailand. Sebelum ditenun, bahan baku diberi warna dengan jalan dicelup dengan bahan warna yang dikehendaki.

Setelah benang diberi warna, lalu ditenun dengan alat yang sederhana. Penempatan benang-benang telah dihitung dengan teliti. Benang yang memanjang atau vertikal disebut lungsi, benang yang ditempatkan melebar atau horizontal disebut benang pakan. Hasil persilangan kedua jenis benang ini terangkai menjadi motif kain. Karena rumitnya proses bertenun ini, sehelai kain dapat diselesaikan dalam waktu berbulan-bulan (3-6 bulan) (Maya, wawancara 20 Desember 2019). Dan untuk proses tahapan pembuatan kain songket Palembang berikutnya dapat dilihat pada bab dua, ini dilakukan agar tidak terjadi pengulangan pembahasan.

Apabila dicermati dalam proses pembentukan sebuah kain songket motif nago besaung memerlukan keterampilan dan kesabaran yang tinggi karena cukup rumit. Sebelum kegiatan menenun benar-benar dimulai, berbagai pola ikatan benang lungsi, yang bersamasama dengan pakan-pakan tambahan terlebih dahulu dibuat rancangannya. Ini dilakukan dengan merapikan jajaran benang lungsi lalu menghitung jumlahnya. Kemudian barisan lungsi yang akan terangkat tatkala proses pembentukkan ragam hias motif nago besaung berlangsung ditandai pada tempat-tempat tertentu agar pola serta titik-titik persilangannya dengan pakanpakan tambahan tampak jelas. Pada songket Palembang pakan-pakan tambahan dibuat dari benang-benang katun berwarna-warni dan ditenun pada alat tenun gedokan yang dilengkapi dengan sisir.

\section{Kesungguhan (Intensity)}

Menciptakan sebuah kain songket menuntut suatu kemahiran dan ketelitian dalam memilih atau menentukan bahan dan alat yang akan dipergunakan demikian pula halnya dalam mendesain motif yang akan diterapkan. Dengan demikian suatu kesungguhan merupakan bagian penting yang harus tampak pada hal tersebut (seperti yang diatas). Hal demikian tentunya akan berdampak baik, dan 
sebaliknya akan berdampak buruk terhadap karya apabila diabaikan.

Sama halnya dengan songket motif nago beaung yang merupakan hasil karya yang lahir dari melalui suatu renungan yang mendalam terhadap karakter suatu objek (motif) yang digambarkan pada dasar kain songket. Kesungguhan emosional seorang pengkarya songket dapat dilihat dari canggih atau tidaknya alat dan bahan yang dipergunakan.

Dharsono Sony Kartika melalui bukunya Estetika menegaskan bahwa: Kesungguhan suatu benda estetis yang baik harus mempunyai suatu kualitas tertentu yang menonjol dan bukan sekedar sesuatu yang kosong. Tak menjadi soal kualitas apa yang dikandungnya (misalnya suasana suram atau gembira, sifat lembut atau kasar), asalakan merupakan sesuatu yang itensif atau sungguh-sungguh (Moenro Beardsley dalm Darsono, 2007: 63).

Apabila dicermati secara visual bentuk motif nago besaung menampilkan tingkat kesungguhan yang tinggi yang ditunjukkan dalam tingkat kreativitasnya dengan menerapkan berbagai motif (pokok, pengisi, dan isen) yang dikomposisikan sedemikian rupa sehingga akan tampak keharmonisan di dalamnya serta kesungguhan yang dapat dirasakan dari emosional/rasa yang menampilkan sejumlah motif baik motif pokok maupun motif pengisi yang merefleksikan nilai atau makna kehidupan sosial masyarakat Palembang.

\section{SIMPULAN}

Berdasarkan deskripsi di atas maka disimpulkan bahwa pada motif nago besaung akan tampak pembagian bagian elemen-elemennya, sehingga akan tampak motif yang menjadi unsur pokoknya (motif yang berada dibadan kain). Kesatuan yang terlihat dari motif nago besaung tersebut dapat terlihat pada tiga bagian motif, yaitu: 1) motif pokok adalah motif naga, 2) motif pengisi yaiutu mawar sebagai motif pengisi dalam motif pokok, dan melati sebagai motif pengisi luar dan motif isen sebagai penambah nilai estetis. 
Dharsono. Estetika dari Barat Sampai ke Timur. Bandung: Rekayasa sains. 2007.

. Tinjauan Eksistensi Historik dan Makna Filosofis Batik Klasik Sebagai Ekspresi Budaya. Makalah Seminar Batik Nusantara, dalam Festival Batik Nusantara 2007.

Djelantik, A.A.M. Estetika, Suatu Pengantar. Bandung: MSPI. 1999.

Rohendi, Tjetjep. Ekspresi Seni Orang Miskin : Adaptasi Simbolik Terhadap Kemiskinan., ringkasan Disertasi Jakarta: Universitas Indonesia. 1993.

Soegeng Toekio. Mengenal Ragam Hias Indonesia. Bandung: Angkasa. 1994.

Soegeng Toekio. Mengenal Ragam Hias Indonesia. Surakarta: Proyek pengembangan IKI Sub Proyek Aski Surakarta, 1983/1984.

Suwati Kartiwa. Kain Songket Indonesia. Djambatan. 1989.

Ragam Kain Tradisional Indonesia (Tenun Ikat). Jakarta: Gramedia Pustaka Utama, 2007. 